\title{
El arte de la curación en la antigua Mesopotamia
}

\author{
Healing in the ancient Mesopotamia
}

\author{
Piedad Yuste \\ Universidad Nacional de Educación a Distancia - UNED*
}

\begin{abstract}
RESUMEN
ABSTRACT

En este artículo mostramos una In this paper we will discuss the healing panorámica de las prácticas médicas llevadas a cabo en la Antigua Mesopotamia, durante los períodos sumerio, paleobabilónico y asirio. practices carried out in the Ancient Mesopotamian along the Sumerian, Babylonian and Assyrian periods.

PALABRAS CLAVE: Medicina arcaica, medicina en KEYWORDS:

Mesopotamia.

Mesopotamian medicine, early medicine.
\end{abstract}

\section{INTRODUCCIÓN}

A finales del cuarto milenio antes de nuestra era, se estableció en Oriente Próximo, y junto a las desembocaduras de los ríos Tigris y Eúfrates, un pueblo de origen desconocido: el sumerio. Fundaron ciudades como Uruk, Ur, Isin, Larsa, Lagash, Eridu, surgidas alrededor de un templo donde se adoraba al dios local, y gobernadas por un monarca que ejercía el poder apoyándose en un consejo de ancianos y en otro integrado por guerreros, según nos cuenta Samuel Noah Kramer ${ }^{1}$.

\footnotetext{
Departamento de Filosofía de la UNED. Paseo Senda del Rey, 17. 28040 Madrid. E-mail: pyuste@fsof.uned.es.

1 KRAMER, S.N.: 2010, 65.
} 
Con el paso del tiempo, estas gentes impusieron su cultura y su lengua al resto de los grupos humanos asentados en aquel lugar.

Los sumerios inventaron la escritura, a partir de pictogramas que poco a poco fueron estilizándose hasta componer ideogramas y signos fonéticos. Escribían sobre pequeñas tablillas de arcilla, con un cálamo que deslizaban sobre la superficie húmeda de las mismas. Luego, las dejaban secar al sol, o bien las cocían en hornos si querían conservarlas durante mucho tiempo. El sistema de escritura cuneiforme se extendió por toda la región y fue utilizado por asirios, hititas, elamitas y cananeos, quienes adaptaron su lengua a los signos sumerios. A mediados del tercer milenio a C., tribus amoritas avanzaron desde el Norte, mezclándose con los sumerios y absorbiendo su civilización. Sargón logró arrebatar la corona de Uruk a su rey Lugalzagesi, unificó todo el territorio y situó la capital de su reino en Acad o Agadé (2334-2112). Desde entonces, la lengua acadia, de origen semita, fue desplazando progresivamente a la sumeria, aunque ésta permaneció vigente en los templos, la corte y las escuelas. Al período acadio le sucedió un nuevo imperio sumerio, el de la Tercera Dinastía de Ur, inaugurado por Ur-Nammu (aprox. 2144-2121), pero su esplendor sólo duró hasta que Ur cayó en manos de los elamitas (2004 a C.). Simultáneamente, los amoritas continuaban su avance, en oleadas sucesivas, desde los desiertos de Siria y Arabia. La fuerte presión ejercida por todos estos pueblos, desbarató completamente la hegemonía alcanzada en la Tercera Dinastía de Ur y sus territorios fueron repartidos entre los ENSIS locales de las antiguas ciudades sumerias.

Hacia el final del siglo XIX a. C. surgieron tres potentes estados amoritas: Eshnunna, Larsa y Babilonia, junto a otros de menor importancia sometidos, en cierta medida, a la influencia de los primeros. Cuando Hammurabi fue nombrado rey de Babilonia, el mapa político mesopotámico mostraba una creciente inestabilidad que el nuevo soberano supo contener, expandiendo su dominio por toda la región, desde los Montes Zagros, en el Este, hasta los desiertos sirio y arábigo en Occidente.

El período comprendido entre los años 2000 y 1600 a. C. se denomina paleobabilónico, según la datación estándar. La sociedad babilónica estaba fuertemente estructurada y jerarquizada: alrededor del monarca encontramos a los funcionarios, oficiales y escribas. Las ciudades se componían, además, de comerciantes, artesanos, soldados, campesinos y esclavos. Dependiendo del templo, hallamos, no sólo a los sacerdotes y escribas, también a los astrónomos, exorcistas y médicos. Según parece, existía una enseñanza civil y otra religiosa, la primera impartida en las escuelas y la segunda en los templos y lugares de culto. En las escuelas, anexas al palacio, se enseñaba la escritura cuneiforme, ambas lenguas sumeria y acadia $^{2}$, cálculo, contabilidad, agrimensura, poesía y leyes. En los templos se instruía a la casta sacerdotal y a los que ejercerían el oficio de sanadores, astró-

2 La lengua babilónica y la asiria eran dialectos del acadio. Distinguimos la escritura sumeria de la acadia de la siguiente manera: las palabras sumerias las escribimos con letras mayúsculas, mientras para las acadias utilizamos cursivas. Las frases entre corchetes indican fragmentos perdidos de los textos y las que escribimos entre paréntesis son expresiones o palabras añadidas por los editores para 
logos y magos, casi siempre desempeñados por los miembros de una misma familia. Conocemos todo esto gracias a la enorme cantidad de tablillas y fragmentos que los arqueólogos han conseguido desenterrar en los yacimientos o tells de las antiguas ciudades de Babilonia, Nippur, Uruk (Warka), Sippar, Hattusa (Boghazköy), etc. La mayoría de estos documentos proceden de las escuelas del período paleobabilónico. En éstas, los alumnos practicaban realizando copias de los textos más relevantes.

Entre 1363 y 627 a. C., los asirios dominaron los territorios que hoy en día corresponden a Irak, Siria, Líbano, Israel, Palestina y parte de Irán y Turquía. Muchos de sus monarcas protegieron las artes y las ciencias, como Senaquerib (668627), quien ordenó traer especies raras de animales y plantas desde todas las partes del mundo conocido, e importó algodón desde la India. En Nínive se ha descubierto lo que fue la biblioteca más antigua de la historia, perteneciente al rey asirio Asurbanipal (668-627 BC) y la cual contenía más de 20.000 tablillas, en su mayoría textos literarios, científicos y sapienciales, procedentes de los registros y archivos de las ciudades sometidas. Muchos de estos documentos eran copias de otros más antiguos y catálogos o referencias a obras más extensas. Poco después de la muerte de Asurbanipal, un jefe de estirpe caldea logró proclamarse rey de Babilonia. En el año 612 a. de C., y con la ayuda de los Medos, los babilonios eliminaron y masacraron a los asirios, arrasando la ciudad de Nínive y destruyendo su templo. Desde entonces, los asirios apenas consiguieron conservar parte de su tradición científica.

\section{TEXTOS Y PRÁCTICAS MÉDICAS}

Hasta el momento, no disponemos de textos teóricos mesopotámicos ${ }^{3}$. Los expertos y técnicos en matemáticas, astronomía, ingeniería y medicina, únicamente dejaron constancia de su saber práctico: series de problemas y tablas numéricas; mediciones de las posiciones relativas de las estrellas, la Luna y los planetas; conjuntos de presagios, plegarias y exorcismos; tratados médicos ${ }^{4}$. Estos podían ser de tres clases: terapéuticos, farmacológicos y series de diagnósticos y pronósticos.

El documento médico más antiguo que conservamos data del período Neosumerio (2112-2004 a C), es un repertorio farmacológico ${ }^{5}$ que recoge conocimientos procedentes de la tradición terapéutica sumeria. Posiblemente, era un manual utilizado por el sanador o AZU. En él se incluyen remedios concretos para aliviar algunas dolencias, sin detallar las proporciones de los ingredientes ni su posología.

aclarar el significado original. Acerca de la escritura cuneiforme leer a MARGUERON, J.C.: 1996 y STEMPEL, R.: 2004. Sobre la historia cultural y social de los pueblos asentados en Mesopotamia, ver, por ejemplo, KLIMA, J.: 1989; NEMET-NEJAT, K. R.: 1998; OPPENHEIM, L.: 2010; ROUX, G.: 1998; SANMARTÍN, J.: 2003. Respecto a las medicinas de la antigüedad, BROTHWELL, D.; SANDISON, A.T. (eds.): 1967 y RUIZ BREMÓN, M. Y SAN NICOLÁS, M.P.: 2008.

3 MARGUERON, J.C.:1996, 460.

4 Editados por KÖCHER, F.: 1963-1980.

5 KRAMER, S. N.: 2010, 95-104. 
Los elementos nombrados son de origen vegetal y se utilizan tanto las semillas como las raíces, tallo, corteza y hojas de esos productos. El tratado nombra sustancias procedentes del mirto, cedro, palmera datilera, higuera, sauce, etc. También se mencionan alimentos procedentes de animales, como la miel y la leche. Minerales: salitre, sal común, arcilla de río, aceite de mar. Algunos de estos elementos son todavía desconocidos para nosotros. Uno de los productos más recomendados en este tipo de tratados y que actúa como excipiente es la cerveza, bebida de uso frecuente en las diversas sociedades asentadas en Mesopotamia. En ocasiones, aparecen referencias a sustancias de origen animal: piel de serpiente, caparazón de tortuga..., pero estas se empleaban en los exorcismos y encantamientos, para ahuyentar al demonio causante del mal. Otro texto del mismo período, y procedente de Ebla (Siria), detalla el instrumental médico con el que contaba el AZU para llevar a cabo su oficio. Se trataba de hojas de bronce, curvadas o rectas, con un peso de entre 2 y 3 siclos (aproximadamente, de 16 a 24 gramos); lancetas para intervenir en las dolencias oculares; fórceps para asistir a las parturientas; un pequeño martillo con el que comprobar la calidad de los reflejos; vidrios pulimentados para examinar la piel y los tejidos ${ }^{6}$.

Durante el período paleobabilónico, el arte de la sanación se desempeñaba de dos maneras distintas. Existían los exorcistas, llamados šipu, quienes hacía un exhaustivo examen del paciente y de su entorno, observando cada detalle: el pulso, las secreciones, el color de la piel, el semblante, la lengua, los ojos, los olores desprendidos... En vista de lo observado, emitían un diagnóstico de la enfermedad y su pronóstico. Recomendaban remedios y bebedizos, si el enfermo tenía cura; pero se abstenían de comenzar el tratamiento si el paciente estaba desahuciado, aunque podían recomendarle fármacos para aliviar su sufrimiento. En última instancia, recurrían a la ayuda de los dioses, instigadores del mal o, al menos, tolerantes con él, pues la causa del mismo podía ser la infracción de un tabú o norma. En ese caso, la curación dependía del arrepentimiento del infractor, y el šipu elevaba plegarias al dios responsable de la enfermedad, mientras atendía al enfermo con sorprendentes rituales apotropaicos y hechizos.

Los terapeutas o ašu, llevaban a cabo una práctica más empírica, recomendando terapias de origen vegetal, animal o mineral; suministrando pócimas, aplicando bálsamos y emplastos, curando heridas y lesiones, restaurando huesos rotos, administrando antídotos contra las mordeduras de serpientes y las picaduras de los escorpiones. No obstante, los enfermos se dirigían a uno u otro especialista, dependiendo de su mal.

A diferencia de lo que ocurría en el antiguo Egipto, en Mesopotamia no se practicaban momificaciones; tampoco se hacían autopsias ni disecciones. Tan sólo el barû o adivino, inspeccionaba el interior del cuerpo de los animales ofrecidos a los dioses; examinaba qué órganos estaban marcados por el dedo de la divinidad, a modo de presagio o advertencia; anotaba malformaciones y coloraciones inusuales de los intestinos y el hígado. Scurlock y Andersen comentan que, pro-

\footnotetext{
${ }^{6}$ KINNIER WILSON, J. V.: 1967, 195; SCURLOK, J. \& ANDERSEN, B.: 2005, 6.
} 
bablemente, los médicos asirios no se habrían resistido a investigar el interior de los enfermos que habían fallecido a causa de enfermedades insólitas o desconocidas $^{7}$. Pero, hasta el momento, no tenemos constancia de ello.

Los médicos babilonios disponían de tratados terapéuticos, en los que se mencionaban el remedio, la enfermedad y su tratamiento específico. Todos estos textos tienen la misma estructura en tres columnas y los hay de tres clases, según la naturaleza (šikinšu) del ingrediente recomendado sea vegetal (sammu šikinšu), mineral (abnu šikinšu) o animal (șeru šikinšu). Veamos un ejemplo tomado de Erica Reiner ${ }^{8}$ :

- Azafrán amarillo / para la constricción de la vejiga / machacar, administrar como poción en cerveza fina.

- Kaniš-bellota / para lo mismo / machacar, administrar como poción en cerveza fina.

- Ajo / para lo mismo / machacar, administrar como poción en cerveza fina.

- Pistacho-hierba / hierba para los pulmones / machacar, administrar como poción sin comer.

Algunos de los manuales terapéuticos se ordenaban según el lugar o asiento (šiknu) de la enfermedad (dimitu), generalmente, estos eran el corazón, los pulmones, el vientre y los riñones. Así, había remedios contra la fiebre, la tos, los dolores de cabeza, afecciones de los ojos, cólicos, entumecimiento de las extremidades, etc.:

«Si un hombre tose, haz cocer arnoglosa cuando está todavía verde como las judías; mézclala con leche, ajo y aceite fino; que la beba en ayunas y sanará.»

«Si el estómago de un hombre está en fuego, si no puede soportar bebida ni comida, machaca semillas de tamarisco, mézclalas con miel y mantequilla fundida, que el enfermo lo coma y sanará.»

"Si un hombre tiene reuma..., mezcla palomina, cantáridas, excrementos de gacela, en la cerveza kurunnu; extiende la mezcla en una tela, y colócala en su pecho y en la base de sus pulmones; déjala así durante tres días y él sanará.»"

Las enfermedades de la mujer y el cuidado de los recién nacidos requería profesionales especializados y parteras, que hacían un seguimiento del período de gestación, prescribían recetas contra la esterilidad o practicaban pruebas de embarazo. ${ }^{10}$

Otra clase de tratado médico es el que describe los síntomas de las enfermedades y sus respectivos pronósticos. Conservamos un manual de estas características y, según se indica en el colofón, fue escrito por Esagil-kin-apli, de

7 SCURLOCK, J. \& ANDERSEN, B.: 2005, 9.

8 REINER, E.: 1995, 29

9 MARCOS, F. y SANTOS, M.: 1980, p. 66.

10 REINER, E.: 1995, 41 y 1982. 
Borsippa, un šipu que vivió durante el mandato del rey asirio Adad-apla-iddina (1069-1046 BC), el cual recoge aquí parte de la tradición médica acumulada hasta entonces. René Labat (en Traité Akkadien de diagnostics et pronostics médicaux) editó en francés lo que consiguió recuperar de las 40 tablillas, con más de 5000 líneas, que componían originalmente este tratado, en cuyo incipit leemos: «Cuando el exorcista va a la casa de la persona enferma...» («en ma anta $b t$ marsi šipu illku...»" ${ }^{11}$. En inglés recibe el nombre de Diagnostics Pronostics Series (DPS). JoAnn Scurlock y Burton Andersen han preparado una excelente versión de esta obra, con transliteraciones, traducciones, anotaciones, apéndices, bibliografía e índices. A partir de las sintomatologías distribuidas en este manual, los autores han logrado identificar muchas enfermedades; algunas, de carácter infeccioso (malaria, tuberculosis, difteria, faringitis, neumonía, tétanos, cólera, rabia, varicela, hepatitis, herpes, lepra, etc.); otras, causadas por transmisión sexual (gonorrea, sífilis, infecciones del tracto urinario...); asimismo, patologías ocasionadas por parásitos, falta de higiene, contagio, heridas y malformaciones. También se describen enfermedades propias de la vejez, como el parkinson, la demencia, trastornos de la memoria. Incluye además referencias a dolencias nerviosas, problemas digestivos, afecciones mentales, insuficiencias respiratorias, arritmias, etc. Las dos primeras tablillas del manual tienen un marcado carácter mágico, pero las restantes son un ejemplo de precisión en la descripción de los síntomas, examen del enfermo y dictamen del pronóstico: «él morirá» o «él sanará»:

«Si un hombre sufre una ictericia grave, si tiene la cabeza, el rostro, el cuerpo y la raíz de su lengua enteramente negros, el médico no aproximará la mano; este hombre morirá; no puede sanar. ${ }^{12}$

El Tratado de diagnósticos y pronósticos no incluye tratamientos ni recomendaciones, a excepción de las advertencias formuladas en relación a cierto tipo de enfermedades «caídas del cielo», o que deben su aparición a la «mano de un fantasma, o de un dios o diosa». Los médicos asirios supieron distinguir entre los signos específicos de una dolencia y los síntomas que refiere el enfermo, muchos de los cuales no coincidían a veces, como cuando el paciente afirmaba tener frío y, sin embargo, su temperatura parecía elevada:

«Si fiebre [...] una persona (y) él continuamente tiene calor y tiene frío, cuando come pan y bebe cerveza vomita (y su estómago) está continuamente alterado, la carne de arriba está fría (pero) sus huesos de abajo le arden, esta persona está quemada por ș tu (fiebre) y tiene li'bu, para curarle... ${ }^{13}$.

11 Edición crítica a cargo de HEEBEL, N. P.: 2000. Una versión comentada de este tratado la encontramos en SCURLOCK, J. \& ANDERSEN, B.: 2005. Aquí los autores distribuyen las referencias según las respectivas etiologías y grupos de enfermedades.

12 MARCOS, F. y SANTOS, M.: 1980, p. 66.

13 BAM 146, rev. líneas 43-46 (SCURLOCK, J. \& ANDERESEN, B.: 2005, xix y 27). Los médicos de Mesopotamia distinguían cinco niveles de temperatura corporal: normal (mitbaru), tibia (babbaš), caliente (ummu), muy caliente (dannu) y ardiente (șarbu). También sabían que la temperatura ascendía a lo largo de la tarde. 
Asimismo, conservamos dos copias de un catálogo de esta manual. En él se registran los incipit correspondientes a las 40 tablillas, consignando además el número de líneas que contiene cada una de ellas. Es muy importante observar que su autor (probablemente, el mismo Esagil) distribuyó el manual en seis secciones. Las dos primeras tablillas del DPS, registran posibles sucesos y signos premonitorios advertidos por el šipu cuando se dirige a la casa del enfermo. Las restantes tablillas recogen juicios clínicos de las dolencias y enfermedades conocidas en la época:

- III a XIV. Examen físico del enfermo, de la cabeza a los pies. Se hace un repaso de los males que afectan al cráneo, como la fiebre, heridas y dolor; aspecto del cabello; heridas y afecciones en los ojos, nariz, orejas, boca, dientes y lengua; temblores y rigidez en el cuello; afecciones en el pecho y la respiración; brazos, manos, dedos, muñecas y codos; abdomen, epigastrio, intestinos, cadera, ingles, nalgas, ano, pene, testículos, excrementos, orina, piernas, rodillas y pies.

- XV y XVI. Evolución de la enfermedad a lo largo de los días. Síntomas que afectan a las personas que han cumplido setenta años.

- XVII. Episodios que atraviesa la enfermedad en un mismo día.

- XVIII. Estados febriles (s tu).

- XIX, XX y XXI. Distinción entre las enfermedades que acusan fiebre de las que no lo hacen.

- XXII y XXIII. Enfermedades infecciosas.

- XXVI a XXX. Enfermedades que afectan al sistema nervioso.

- XXXI. Fiebres.

- XXXIII. Lesiones de la piel

- XXXVI a XL. Dolencias y cuidados de la mujer y de los niños.

Scurlock y Andersen observan cómo los médicos distribuyen las dolencias de este manual siguiendo un principio organizativo ${ }^{14}$. Así, el šipu (o el aprendiz de šipu), una vez examinado y escuchado al paciente, acudiría al registro o conjunto de registros que describen los síntomas de la enfermedad, atendiendo, además, al número de días que duraba ésta, o a los tipos de fiebre, o a la evolución diaria de los signos de esa patología. Emitiría un diagnóstico y, si la enfermedad tenía cura, indicaría qué remedios aplicar y suministrar, seguramente, recurriendo a un texto terapéutico. Asimismo, consultando el manual, el šipu era consciente de qué fantasma, dios o diosa enviaba la dolencia, actuando entonces en consecuencia mediante prácticas rituales o namburbi.

Hemos recuperado otro texto de diagnósticos y pronósticos más antiguo que el anterior. Según el incipit: «si te acercas a un hombre enfermo.... U Únicamente guardamos dos fragmentos del mismo: uno procedente de Nippur, y el otro hallado

14 Ibid., p. 575. 
en las excavaciones de Sultantepe, un enclave asirio de Turquía ${ }^{15}$. En opinión de Scurlock y Andersen, los textos de diagnósticos y pronósticos surgieron en el período medioasirio (siglos XIV al XII a C.), cuando los conocimientos médicos eran ya tan abundantes como para necesitar repartir las tareas de los sanadores y diferenciar sus respectivos manuales técnicos ${ }^{16}$. Así, los šipu pasarían a ser los auténticos médicos, mientras los ašu desempeñarían exclusivamente funciones farmacéuticas o herbarias. En una vivienda de la antigua ciudad de Assur se ha encontrado un texto neoasirio en el que se mencionan las actividades realizadas por Kișir-Aššur, hijo de Nabû-b ssunu, y por su sobrino Kișir- Nabû, hijo a su vez de Šamaš-ibni, ambos šipu del templo dedicado al dios Assur.

Magia y curación muchas veces iban de la mano. Los babilonios creían que las propiedades curativas de los fármacos dependían del ritual con el que estos se elaboraban y suministraban. Según explica Erica Reiner, «la medicina debía ser preparada bajo la influencia de las estrellas benefactoras y administrada en el momento propicio». El texto aconsejaba al médico: «deja reposar (el medicamento) por la noche bajo las estrellas», o «por la noche, colócalo frente a la estrella $\mathrm{Ca}$ bra» ${ }^{17}$. Cabra es Vega, la estrella más brillante de la constelación Lira; en aquella época, la celestial manifestación de Gula, la diosa de la salud. El ašu cubría su cabeza al recolectar la hierba, y lo hacía de noche, en la oscuridad, cuando la posición de los astros era favorable. También tapaba la planta con un paño y trazaba un círculo de harina a su alrededor. Así, la diosa infundía el poder curativo a la hierba. Otros métodos terapéuticos consistían en envolver figurillas de arcilla y colgarlas del cuello del enfermo. El ašu recomendaba protegerlas de los fantasmas:»haz una figurilla de un demonio, envuélvela en piel de león, átala y ponla alrededor de su cuello.»18

\section{CLASES DE ENFERMEDADES}

Los babilonios ${ }^{19}$, creían que el lugar donde se genera la actividad mental es el corazón. Por tanto, las enfermedades que hoy en día consideramos mentales o nerviosas se achacaban a este órgano. Algunos de los síntomas serían: «no en completa posesión de sus facultades», "dificultad para hablar», "él deambula (confundido)", "él no sabe dónde está» ${ }^{20}$. Por el contrario, las dolencias que aquejaban al cerebro sólo podían venir de lesiones y traumatismos producidos en esta zona. El cerebro era una parte más de la cabeza, como son los ojos, la

15 STOL, M.: 1992, 91. Aquí el autor comenta que Esagil redactó su DPS a modo de rectificación de este texto.

16 SCURLOCK, J. \& ANDERSEN, B.: 2005, 6.

17 REINER, E.: 1995, 48. Fragmentos como estos se han encontrado en textos hititas del siglo XIII a C., en la antigua capital de su reino: Hattuša. Fueron escritos en acadio y, seguramente, eran copias de otros más antiguos procedentes de Babilonia.

18 Ibidem.

19 GELLER, M.J.: 2004, 36.

20 Ver, por ejemplo, AOAT 43, líneas 255, 200 y 152; SCURLOCK, J. \& ANDERSEN, B.: 2005, 531. 
boca, la nariz y las orejas. Uno de los males más comunes que afectan a la cabeza es la fiebre; otros son los ojos ensangrentados, la vista nublada, la insolación, etc. Leemos: «si los ojos de un hombre están enfermos...», «si el cerebro de un hombre contiene calor...», «si las sienes de una persona le duelen...» ${ }^{21}$.

Muchas de estas enfermedades de origen neurológico iban acompañadas de temblores, entumecimiento, parálisis y ataques repentinos. Los babilonios distinguieron un grupo de dolencias a las que nosotros identificamos con la epilepsia; estas son examinadas en la cuarta sección del DPS:

«Si el paciente gira continuamente su cabeza a la izquierda, sus manos y pies están inmóviles, cierra y gira sus ojos, y la baba fluye de su boca, $(y)$ hace mucho ruido, AN.TA.ŠUB.BA.» 22

Así, denominaron con el término sumerio "AN.TA.ŠUB.BA» al ataque repentino «caído del cielo», mientras la enfermedad de carácter crónico se reconocía con la expresión acadia «bennu»»3:

«Si su pecho le duele continuamente, deja de comer y de beber mucho, (y) está permanentemente acostado, sufre ataques continuamente, bennu aflige a esa persona. Le aflige en la puerta, en el patio o en el río» ${ }^{24}$

Pero hay otras palabras acadias relacionadas con esta clase de dolencias: «miqtu» (algo que ha caído abajo), "bajjattu» (acceso), «șibtu» (ataque), aunque no sabemos si se refieren a diferentes estadios, modalidades o grados de intensidad de estas enfermedades.

La palabra sumeria «AN.TA.ŠUB.BA» también aparece cuando se describen males que afectan al cuello, espalda y corazón. Según se desprende de los textos, la variedad «AN.TA.ŠUB.BA» es mucho más grave y tiene fatales consecuencias. Lo mismo sucede cuando el "miqtu» ataca a los recién nacidos, estos dejan de mamar y mueren:

«Si un bebé tan pronto como nace (y) pasados dos o tres días, (su estómago) no acepta la leche y miqtu cae sobre él como por la mano de un dios, la mano de Ištar. El ladrón le ha tocado; él morirá.»25

\section{Bennu era una afección contemplada en el Código de Hammurabi:}

«Si un hombre compra un esclavo o esclava y antes de que haya transcurrido un mes bennu cae sobre él, el comprador devolverá el esclavo a su vendedor y el comprador obtendrá la plata que hubiera pagado. ${ }^{26}$

21 BAM 482 i rev. línea 64. Ibid., p. 285.

22 DPS X A anv. líneas 4-6. Ibid., p.305

23 STOL, M.: 1992, 92.

24 Tablilla STT 89, líneas 192-195. Ibid., p. 97; SCURLOCK \& ANDERSEN, B.: 2005, 84

25 DPS XL A, 26-27. SCURLOCK, J. \& ANDERSEN, B.: 2005, 316.

26 Artículo 278. LARA PEINADO, F.: 1986. 
También se menciona en el Catálogo de estrellas, MUL.APIN: «si la estrella de Marduk mira el cuerpo de un hombre, bennu le atacará.»27

Vemos entonces cómo algunas enfermedades caían del cielo o eran provocadas por la mano de un dios o de un demonio, aunque sus causas directas se debieran a heridas y traumatismos:

- «Si los músculos del cuello de una persona le duelen, la mano de un fantasma.»

— «Si está herido en la cabeza y, en consecuencia, sus ojos están nublados, la mano de Ningirsu.»

— Si su mente está alterada continuamente, la mano de Šamaš; él ha violado un tabú.

— «Si le duele constantemente la cabeza y no tiene fiebre, la mano de Ištar.» ${ }^{28}$

Por tanto, su etiología era de naturaleza divina: caen del cielo o vienen de las estrellas; a modo de «semillas del cielo», como la ictericia, enviada en forma de lluvia por Nergal, el dios de las pestilencias. A veces, es la saliva del dios; en ocasiones, son sus lágrimas, que se derraman y esparcen sobre los seres humanos y el ganado, ocasionándoles el mal. De la modalidad más grave de epilepsia se culpa al «engendro de Šulpaea». Este era un dios secundario ligado a Júpiter, la estrella del dios Marduk. Aquellos que ofendían al dios eran castigados, aunque no directamente por él, sino a través de su lacayo Šulpaea, quien vertía el mal sobre el infractor o sobre su descendencia. Algunos casos eran tan graves que el ašipu recomendaba deshacerse del afectado, para evitar que el daño se extendiera a toda la familia:

- «[Si el engendro de] Šulpaea ha nacido con él, la casa de su padre se dispersará a sus pies; [para que ésta no se disperse], arrójale vivo al río y su mal se irá. [Su signo es ese, desde] el momento de su nacimiento, él no llora ni grita y está rígido...»

- «Si un mal le aflige mientras anda por la calle y cuando le aflige sus manos y sus pies se retuercen contra el suelo, sus ojos se oscurecen, su nariz se contrae, (y) muerde su ropa, el engendro de Šulpaea. Su signo (presagia) la destrucción de la casa de su padre. Su padre y su madre llevarán el castigo. Para que esto no ocurra, entiérrale vivo en la tierra; su mal se disipará.»

En otros documentos se mencionaba al demonio LUGAL-ÙR.RA, como causante de algunos de estos ataques. También se le conocía como «el señor del tejado», porque atacaba a las personas que acudían a ese lugar durante la noche:

27 STOL, M.: 1992, 16. MUL.APIN es la constelación del Triángulo. Los asirios escribieron este catálogo de estrellas con fines astrológicos; data del año 1000 a de C., aunque la copia que conservamos se escribió en torno al año 687 a C. (REINER, E.: 1995).

28 DPS: X A, línea 19. III C, rev línea 15. XXII, 55 a. III C, anv. Línea 35 (SCURLOCK, J. \& ANDERSEN, B.: 2005, 285). 
«si un hombre se aproxima a una mujer en el tejado, un demonio le golpeará.» ${ }^{29} \mathrm{El}$ rabișu es un diablo mirón que hostiga a sus víctimas en los lugares más recónditos y alejados:

«Si cuando sale del agua, su cuerpo se paraliza y se siente girar y cae al suelo, ha sido golpeado por el demonio del río...» ${ }^{30}$

Hoy en día, se han podido relacionar muchos de los síntomas descritos en el DPS con enfermedades conocidas. Entre ellas reconocemos las huellas del alcoholismo:

«Si sus palabras son ininteligibles y continuamente pide cerveza (y ha estado enfermo) durante diez días [...]. Si sus palabras son ininteligibles y continuamente pide vino a intervalos regulares (y él ha estado enfermo) [durante diez días...]. ."31

Son especialmente interesantes las referencias dedicadas a las enfermedades mentales, aquellas en las que una persona sana actúa de manera enfermiza: «si una persona está sana pero su comportamiento está enfermo ${ }^{32}$. Entre ellas encontramos las producidas por preocupaciones y estrés: insomnio, dolores de cabeza, ansiedad, pesadillas, rechinar de dientes, hablar o reír entre sueños, soñar con personas fallecidas. Incluso el «mal de amores» se consideraba un trastorno mental, pues provocaba inquietud y malestar:

«Si el desaliento cae continuamente sobre él, su respiración continuamente es cortada, come pan (y) bebe agua o cerveza pero no le agrada, dice jay mi corazón!, y está abatido, está enfermo con el mal de amores.»33

Pero el ašipu describe además otras muchas dolencias que apuntan a graves alteraciones psicosomáticas y que vienen acompañadas de trastornos en la respiración y el ritmo cardíaco, dolores intestinales, vómitos, etc. En ocasiones, culpa de ello al enfermo, quien ha quebrantado un tabú, como vemos en el caso del incesto:

«Si una mujer permanece fuera por la noche [cuando] está sana y cuando está enferma, el hijo de su dios se ha aproximado a ella (sexualmente).» ${ }^{34}$

O se trata de males que causan cambios de humor en el paciente y que no se corresponden con su situación externa real:

«Si una persona continuamente tiene una sensación de presión en su pecho y abatimiento (y) su corazón piensa falsedades...»35

29 Ver STOL, M.: 1992, 16.

30 DPS: XXVII, línea 25 (SCURLOCK, J \& ANDERSEN, B.: 2005, 442).

31 DPS VII B, rev. líneas 13-14 (ibid., p. 361).

32 Texto contenido en la tablilla BM 64174, 9, registrada en el Museo Británico (BAM 326 ii, rev. 7).

33 DPS XXII, líneas 8-9 ( SCURLOCK, J. ANDERSEN, B.: 2005,373 ).

34 DPS XXXVII A, anv. línea 20 (SCURLOCK, J. ANDERSEN, B.: 2005, 373).

35 BAM 316 iii, rev. líneas 23-24 (ibid., p. 382). 
«Si se pone y se quita la ropa, continuamente grita, habla mucho, no devuelve el pan y la cerveza, de modo que puede comer pero no puede dormir, la mano de Ištar se ha posado (sobre él); sanará. ${ }^{36}$

También encontramos trastornos psicóticos, esquizofrenias y paranoias:

«Si una persona está continuamente triste, está levantada de día y de noche, sufre serias pérdidas de dinero y no consigue beneficios, la gente le calumnia, la gente que habla con él no le dice la verdad, la gente habla mal de él a sus espaldas; ellos no le ven en el lugar en el que se encuentra, sus sueños son inquietos, continuamente ve en sueños a personas muertas, una sensación de aplastamiento se aloja en su pecho...(los dioses y las diosas están enojados con él, se ha hecho brujería contra él, ha sido maldecido ante el dios y la diosa), sus deseos son confusos, dios, rey, patrón y príncipe le ocasionan pesar, no encuentra respuesta a sus problemas fuera del adivino o del vidente, incluso después de siete (intentos), nadie le escucha... ${ }^{37}$

Y otras enfermedades cerebrales, como el Parkinson, síndrome de Gilles de la Tourette, corea («baile de San Vito»), demencia y autismo. Incluso, se distingue el estado comatoso de un simple desmayo y de la narcolepsia (gallû). En la mayoría de los casos, se culpa al paciente de estas dolencias, o a sus progenitores, por haber violado alguna regla de convivencia; en última instancia, son los dioses quienes envían el mal.

Las últimas tablillas del Tratado de diagnósticos y pronósticos están dedicadas al cuidado de la mujer y de los niños. El ašipu especialista en obstetricia y ginecología hacia exámenes regulares de las pacientes, bien para comprobar el desarrollo del feto, bien para recomendar algún tipo de tratamiento para prevenir o curar la esterilidad. De la lectura de los textos se desprende que disponían de un instrumento para realizar inspecciones vaginales:

«Si el útero de una mujer en edad fértil está brillante, ella está fecundada con un niño que no estará sano. ${ }^{38}$

En algunos documentos terapéuticos, encontramos referencias que señalan casos de interrupción del embarazo; bien porque el feto muere: «durante siete meses había estado un niño en mi útero, (pero) desde hace un mes el niño de mi útero está muerto. ${ }^{39} \mathrm{O}$ bien, por otras causas más mundanas. En todas esas situaciones, el médico recomienda utilizar ciertas plantas para hacer caer al feto ${ }^{40}$, aunque su labor principal es impedir que esto ocurra. En algunos textos se indica cómo prevenir el embarazo: «La joven sacerdotisa tendrá que realizar (su amor

${ }^{36}$ DPS XXVI, rev. líneas 78-79 (ibid., p. 383).

37 Ibid., p. 374.

38 DPS XXXVI A, línea 102 (SCURLOCK, J. ANDERSEN, B.: 2005, 259).

39 SCURLOCK, J. ANDERSEN, B.: 2005, 261.

40 STOL, M \& WIGERMANN , F.A.M. 2000, 42 y ss. 
prohibido) el coito anal para no quedar encinta. ${ }^{41}$ También encontramos pruebas de embarazo:

«Envuelve medio siclo de planta blanca; un cuarto de siclo de alumbre, y [...en un mechón de lana]. Ponlo [en] su vagina. [Ella lo conserva en ese lugar] toda la noche. [A la mañana siguiente...] lávalo. Si el mechón de lana está rojo o con rayas de sangre roja, [esa mujer está embarazada]. Si el mechón de lana está verde, esa mujer no está embarazada. ${ }^{42}$

El momento del parto estaba impregnado de misterio y de magia. La comadrona llevaba a cabo el ritual: cubría la cabeza de la parturienta con un paño y trazaba un círculo de harina a su alrededor; mientras, entonaba plegarias y rezos. El médico actuaba si el alumbramiento se presentaba difícil. Inmediatamente después, la madre y el niño seguían recibiendo los cuidados de este especialista.

Las prácticas quirúrgicas datan del 3.000 a C. Los cirujanos ocupaban un nivel social parecido al de otras actividades manuales, por debajo de los asû y ašipu. En el Código de Hammurabi se regulan los honorarios y obligaciones de los médicos y cirujanos, así como se especifican los castigos ocasionados por ejercer una mala praxis ${ }^{43}$.

- Ley 218: Si un médico hizo una operación grave con el bisturí de bronce y le ha hecho morir, o bien si le operó de una catarata en el ojo y destruyó el ojo de este hombre, se cortarán sus manos.

- Ley 219: Si un médico hizo una operación grave con el bisturí de bronce e hizo morir al esclavo de un awilum (hombre libre), dará otro esclavo equivalente.

- Ley 220: Si operó una catarata con el bisturí de bronce y ha destruido su ojo, pagará en plata la mitad de su precio.

- Ley 221: Si un médico curó un miembro quebrado de un hombre libre, y ha hecho revivir una víscera enferma, el paciente dará al médico cinco siclos de plata.

- Ley 222: Si es el hijo de un awilum, dará tres siclos de plata.

- Ley 223: Si es el esclavo de un hombre libre, el amo dará al médico dos siclos de plata.

- Ley 226: Si un cirujano, sin autorización del dueño de un esclavo, ha sacado la marca de esclavo inalienable, se le cortarán las manos.

- Ley 227: Si un hombre engañó a un cirujano y si él (el cirujano) ha sacado la marca del esclavo inalienable, este hombre será muerto en su puerta y se le enterrará. El cirujano, que no ha actuado a sabiendas, jurará y será libre.

41 SCURLOCK, J. ANDERSEN, B.: 2005, 261.

42 UET 7. 123, líneas 1-4 (ibid., p. 262).

43 LARA PEINADO, F.: 1986. 


\section{CONCLUSIÓN}

En este trabajo hemos mostrado una semblanza de las prácticas curativas llevadas a cabo en la Antigua Mesopotamia. Los textos apuntan a una tradición de terapeutas iniciada a mediados del cuarto milenio a de C., probablemente, durante los períodos de las dinastías arcaicas de Uruk. Este conjunto de conocimientos, transmitido oralmente de padres a hijos, o enseñado a muy contados aprendices en las escuelas anexas a los templos, fue recogido sucesivamente por los sanadores de las civilizaciones acadia, babilónica, asiria y caldea. La magia y el exorcismo impregnaron un saber que se apoyaba en el examen clínico, la experiencia y la tradición. Los médicos de estas culturas no supieron - o no pudieron - enunciar hipótesis teóricas a las que ajustar los datos empíricos acumulados en el ejercicio de su profesión, como siglos después hicieron los asclepíadas griegos, al atribuir el origen de las enfermedades al desequilibrio humoral. Los sanadores asirios y babilonios procedieron de manera más arcaica: registrando las manifestaciones y los síntomas de las enfermedades; anotando las dolencias concomitantes; escudriñando al paciente. No conociendo la causa de la enfermedad, creyeron que los dioses enviaban el mal, a modo de represalia contra el enfermo, quien, seguramente, habría quebrantado un juramento o violado alguna regla. Antes de nada, se hacía necesario contentar a los dioses. De ahí las plegarias y ritos, los exorcismos y las ofrendas. Nada nos sorprende: el ser humano actual todavía busca curas milagrosas y achaca su enfermedad a castigos divinos y a conductas improcedentes. A veces, se conforma con lo que le ha venido (del cielo) y no busca la curación, porque ve en su dolencia el castigo impuesto por su falta.

\section{BIBLIOGRAFÍA}

BOTTÉRO, J. ET AL. (1996). Introducción al antiguo Oriente. De Sumer a la Biblia. BarceIona: Grijalbo-Mondadori.

BROTHWELL, D.; SANDISON, A.T. Eds. (1967). Diseases in Antiquity; a survey of the diseases, injuries, and surgery of early populations, Springfield, Illinois: Charles C. Thomas.

HEEbEL, N. (2000). Babylonische-assyrische Diagnostik, Alter Orient und Altes Testament 43 (AOAT), Münster: Ugartit Verlag.

KINNIER WILSON, J. V. (1967). «Organic diseases in Ancient Mesopotamia», en Diseases in Antiquity, D. Brothwell y A. T. Dandison, eds., Springfield, Illinois: Charles C. Thomas.

KLIMA, J. (1989). Sociedad y cultura en la antigua Mesopotamia. Traducción de Matilde Moreno. Madrid: Akal

KÖCHER, F. (1963-1980). Die Babylonisch-assyrische Medizin in Texten und Untersuchungen (BAM), 4 vols. Berlin, New York: Walter de Gruyter.

KRAMER, S. N. (2010). La historia comienza en Sumer: treinta y neve primeros testimonios de la historia escrita. Madrid: Alianza.

LABAT, R. (1951): Traité akkadien de diagnostics et pronostics médicaux. Paris, Leiden: Académie Internationale d'Histoire des Sciences.

LARA PEINADO, F. (1986). El Código de Hammurabi. Madrid: Tecnos.

MARCO, F.; SANTOS, N. (1980). Textos para la historia del Próximo Oriente Antiguo, vol. II. Universidad de Oviedo.

MARGUERON, J.-C. (1996). Los mesopotámicos. Madrid: Cátedra. 
NEMET-NEJAT, K. R. (1998). Daily Life in Ancient Mesopotamia, Greenwood Press.

OPPENHEIM, L. (2010). La Antigua Mesopotamia: retrato de una civilización extiguida. Madrid: Gredos

REINER, E. (1995). Astral Magic in Babylonia. Philadelphia: The American Philosophical Society.

— (1982). «Babylonian Birth Prognoses»,Zeitschrift für Assyriologie und vorderasiatische Archäologie 72:1, 124-138.

ROUX, Georges (1998). Mesopotamia: historia política, económica y cultural. Madrid: Akal

RUIZ BREMÓN, M.; SAN NICOLÁS, M.P. (2008). Enfermar en la antigüedad. Madrid: UNED.

SANMARTíN, J. (2003). Historia antigua del Próximo Oriente: Mesopotamia y Egipto. Madrid: Akal.

SCURLOCK, J. \& ANDERSEN, B. (2005). Diagnoses in Assyrian and Babylonian Medicine. Urbana, Chicago: University of Illinois Press.

STEMPEL, Reinhard (2004). "La escritura cuneiforme», en La Escritura y el Libro en la Antigüedad, de Bartolomé, J., González, Mํㅡㄹ., Quijada, M. (eds.). Madrid: Ediciones Clásicas (Sociedad Española de Estudios Clásicos)

STOL, M. (1992). Epilepsy in Babylonia. Groningen: STYX Publications.

STOL, M.; WIGGERMANN, F.A.M. (2000). Birth in Babylonia and in Bible: Its Mediterranean setting. Groningen: STYX Publications.

GELLER, M. J. (2004): «West meets East: Early Greek and Babylonian Diagnosis», in H. F. J. Horstmanshoff and M. Stol, Magic and Rationality in Ancient Near Eastern and Graeco-Roman Medicine, Leiden, Boston: Brill, pp. 11-61. 
